ment conducive enough for us to run 24-h shifts; the mothers and their infants; the entire staff of the Medical Research Council Laboratories, The Gambia; Melissa E. Hickman and Marcia A. Rench (Infectious Disease Section, Department of Pediatrics, Baylor College of Medicine) for their contributions; and Richard R. Facklam (CDC) for providing $\beta$-lysin-producing Staphylococcus aureus S5-697.

\section{References}

1. Baker CJ. Edwards MS. Group B streptococcal infections. In: Remington JL, Klein JO, eds. Infectious diseases of the fetus and newborn infant. 4th ed. Philadelphia: WB Saunders, 1994 (in press).

2. Onile BA. Group B streptococcal carriage in Nigeria. Trans R Soc Trop Med Hyg 1980;74:367-70.

3. Faye-Kette AH, Dosso M, Kacou A, et al. Genital carriage of Strepiococcus group B in the pregnant women in Abidjan (lvory Coast). Bull Soc Pathol Exot 1991:84:532-9.

4. Baker CJ, Barret FF. Transmission of group B streptococci among parturient women and their neonates. J Pediatr 1973;83:919-25.
5. Sunna E. el-Daher N. Bustami K, Na'was T. A study of group B streptococcal carrier state during late pregnancy. Trop Geogr Med $1991 ; 43: 161-4$

6. Ferrieri P, Cleary PP, Seeds AE. Epidemiology of group B streptococcal carriage in pregnant women and newborn infants. J Med Microbiol 1977:10:103-14

7. Badri MS, Zaweneh S, Cruz AC, et al. Rectal colonization with group B Streptococcus: relation to vaginal colonization in pregnant women. $\mathrm{J}$ Infect Dis 1977; 135:308-12.

8. Ilogkamp-Koistanje JAA. Geralds LJ, Cals BP. Maternal carriage and neonatal acquisition of group $B$ streptococci. J Infect Dis 1982; 145:800-3

9. Franciosi RA, Knostman JD, Zimmerman RA. Group B streptococcal neonatal and infant infections. J Pediatr 1973;82:707-18.

10. Aber RC, Allen N. Howell JT, Wilkinson HW. Facklam RR. Nosocomial transmission of group B streptococci. Pediatrics 1976;58:34653.

11. Anthony BF, Okada DM, Hobel CJ. Epidemiology of group B Streptococcus: longitudinal observations during pregnancy. I Infect Dis $1978 ; 137: 524-30$.

12. Mani V. Jadhar M, Siradasan K. Thang-velu (P. Rachel M. Prasha I. Maternal and neonatal colonization with group B Sireptococcus and neonatal outcome. Indian Pediatr 1984;21:357-63.

\title{
Lipopolysaccharide (LPS)-Binding Protein in Human Serum Determines the Tumor Necrosis Factor Response of Monocytes to LPS
}

\author{
Philippe Gallay, ${ }^{*}$ Catherine Barras, Peter S. Tobias, \\ Thierry Calandra, Michel Pierre Glauser, \\ and Didier Heumann
}

\author{
Department of Internal Medicine. Division of Infectious Diseases, \\ Lausanne, Suitzerland; Departmen of Immunology, Research Institute \\ of Scripps Clinic, La Jolla, California: Picower Institute. New York
}

\begin{abstract}
Lipopolysaccharide (LPS)-binding protein (LBP) and CD14 represent key elements in monocyte activation by LPS. The mean concentration of LBP was $18.1 \mu \mathrm{g} / \mathrm{mL}$ in normal serum and 40-60 $\mu \mathrm{g} / \mathrm{mL}$ in serum of patients with septic shock, independent of the fact that patients had gram-negative or other infections. Ten percent normal serum presented large concentrations of LPS (in the microgram range) to monocytes. Only when diluted 1:100 was LBP in plasma a limiting factor for monocyte activation, as measured by tumor necrosis factor (TNF) release. When LBP was depleted from serum with anti-LBP antibodies, the resulting serum did not support TNF release of monocytes upon LPS challenge. In conclusion, monocyte activation resulting in TNF secretion was related to LBP, which is abundantly present in normal serum, and elevated two to three times in patients with septic shock.
\end{abstract}

Evidence from in vitro studies implicates serum lipopolysaccharide (LPS)-binding protein (LBP) and monocyte CDI4 as major factors contributing to the LPS-induced acti-

Received 7 March 1994; revised 3 June 1994

Financial support: Fonds National Suisse de la Recherche Scientifique (32-30265.90 and 3200-039763.93).

Informed consent was obtained from patients or their relatives for blood collection.

Reprints or correspondence: Dr. Didier Heumann. Division of Infectious Diseases, BH-19 CHUV-10I I Lausanne, Switzerland.

* Current affiliation: Salk Institute, La Jolla, California

The Journal of Infectious Diseases 1994;170:1319-22

(C) 1994 by The University of Chicago. All rights reserved.

$0022-1899 / 94 / 7005-0044 \$ 01.00$ vation of monocytes [1-4]. However, it is not clear whether the interaction of LPS with LBP and CD 4 is the major mechanism in triggering monocytes or whether other mechanisms of LPS recognition involving other monocyte receptors [5] or other serum mediators [6] could also be operational. At low concentrations of LPS, tumor necrosis factor (TNF) release by human monocytes appeared to be mostly dependent upon the presence of LBP or septin and CDI $4[1-3,6]$. However, the presence of CDI4 and LBP as a prerequisite for LPS-induced monocyte activation has been questioned. Indeed. secretion of TNF and interleukin- 1 (IL-1) has been observed in the absence of LBP and in CD14-deficient patients [4], implicating the participation of receptors other than CDI4. Using sera from normal donors and patients 
with septic shock, we investigated the process of monocyte activation leading to TNF release by human monocytes with respect to CDI4 and LBP, examining the relationships between the concentration of serum and the presence of CDI4.

\section{Materials and Methods}

Blood. Serum was collected in endotoxin-free tubes at study entry and at day 10 from 77 patients with septic shock [7]. In addition, fresh and outdated samples from 60 normal blood donors were used. Serum was stored at $-70^{\circ} \mathrm{C}$ and underwent up to two freeze-thaw cycles before being assayed.

Materials. Ol11 LPS, unlabeled or labeled with fluorescein isothiocyanate (FITC) was from Sigma (St. Louis), and antiCD14 monoclonal antibody (MAb) MY 4 was from Coulter Immunology (Luton, UK). Human recombinant LBP (rh-LBP) was a gift of R. J. Ulevitch (Scripps Clinic).

Blood from normal donors was collected in endotoxin-free heparin to prepare peripheral blood mononuclear cells (PBMC) by centrifugation over Ficoll-Paque (Pharmacia, Uppsala, Sweden).

$L B P$ depletion. LBP was depleted from serum using $\operatorname{IgG}$ from a goat immunized with rh-LBP [8]. Serum ( $1 \mathrm{~mL}$ ) was treated overnight with $10 \mathrm{mg}$ of protein-G goat $\mathrm{IgG}$ or, as a control, normal goat immune IgG. Immune complexes were eliminated by centrifugation at $13,000 \mathrm{~g}$ for $10 \mathrm{~min}$ at $4^{\circ} \mathrm{C}$.

Binding assay of FITC-LPS to monocyles. PBMC $\left(10^{6}\right)$ were incubated with $1 \mu \mathrm{g} / \mathrm{mL}$ FITC-LPS in $1 \mathrm{~mL}$ of medium enriched with human serum ( $1.0 \%$ or $0.1 \%)$ or with $4 \%$ albumin. Binding of FITC-LPS to monocytes was assessed by flow cytometry [3].

RIA and ELISA for measuring plasma levels of $\angle B P . \quad L B P$ was measured by a sandwich RIA using monophosphoryl lipid A (Ribi Chemicals, Hamilton, MT) as the solid phase and ${ }^{125} \mathrm{I}-\mathrm{la}$ beled IgG directed against rh-LBP to detect captured LBP [9]. LBP was also measured by ELISA made up of two MAbs to LBP [10].

TNF assays. PBMC $\left(0.5 \times 10^{6}\right)$ in $200 \mu \mathrm{L}$ of medium enriched with $1.0 \%$ and $0.1 \%$ serum were stimulated with unlabeled LPS at a concentration of $1 \mathrm{ng} / \mathrm{mL}$. Supernatants were collected for TNF measurements after $4 \mathrm{~h}$ of culture at $37^{\circ} \mathrm{C}$ using a bioassay set up with WEHI cells [11].

Statistical analysis. Measurements of LBP were presented as mean $\pm \mathrm{SD}$. Differences between groups were estimated using a two-tailed Student's $t$ test. Regression analysis was estimated according to the transformation of Fisher [12]

\section{Results}

Determination of $\angle B P$ concentrations. Patients in septic shock had higher LBP concentrations in serum than did normal volunteers, as measured by RIA. The mean concentration of LBP was $18.1 \pm 4.0 \mu \mathrm{g} / \mathrm{mL}$ in normal sera, $54.1 \pm$ $10.2 \mu \mathrm{g} / \mathrm{mL}$ in sera collected at entry from patients with gram-negative shock, and $45.4 \pm 8.7 \mu \mathrm{g} / \mathrm{mL}$ in sera of patients with shock caused by other organisms or with no microbiologic documentation. LBP levels in these 2 groups of patients were higher than levels in normal donors $\left(P<10^{-5}\right)$.
At entry, the mean concentration of LBP was $58.1 \pm 13.7$ $\mu \mathrm{g} / \mathrm{mL}$ in patients who survived gram-negative shock and $52.0 \pm 7.6 \mu \mathrm{g} / \mathrm{mL}$ in patients who died. In patients with septic shock from causes other than gram-negative bacteria, the concentrations of LBP at entry were $52.0 \pm 3.9 \mu \mathrm{g} / \mathrm{mL}$ in patients who survived and $41.2 \pm 12.1 \mu \mathrm{g} / \mathrm{mL}$ in patients who died. These values were statistically similar among groups. Furthermore, these LBP concentrations were in the same range for samples obtained 10 days after the onset of shock: $54.3 \pm 14.6 \mu \mathrm{g} / \mathrm{mL}$ in patients with gram-negative shock: $46.8 \pm 12.7 \mu \mathrm{g} / \mathrm{mL}$ in patients with septic shock from other causes. By statistical analysis, no differences were observed when LBP values were correlated with outcome or with a specific type of infection. In addition, neither the initial level nor the level 10 days after the onset of the disease had a predictive value for survival in individual patients (data not shown).

Correlation of LBP levels measured by RIA and by flow cytometric assay. We previously reported that LBP could be measured in plasma by using its ability to present FITC-LPS to CDI 4 on monocytes [3,9]. Serum-mediated binding of FITC-LPS to monocytes was found to be correlated with LBP concentrations measured by RIA for both normal donors $\left(r=.87, P<10^{-3}\right)$ and for patients with septic shock at study entry $\left(r=.91, P<10^{-3}\right)$. Repeated freeze-thaw cycles of the samples or use of fresh versus outdated plasma did not modify LBP measurements (data not shown).

We pooled normal donor sera (3-6 serum samples/pool) with high (pool A) and low (pool B) LBP activity. By RIA and ELISA, respectively, we measured $39 \pm 3$ and $4 I \pm 16$ $\mu \mathrm{g} / \mathrm{mL} \mathrm{LBP}$ in pool A and $10.5 \pm 2.1$ and $11 \pm 5 \mu \mathrm{g} / \mathrm{mL}$ LBP in pool $B$.

Effect of LBP depletion on the fow cytometric assay. We confirmed that the flow cytometric assay actually measured LBP by depletion experiments (table I). Treatment of serum with anti-LBP but not with control IgG suppressed the serum-mediated binding of FITC-LPS to monocytes to a level similar to that observed in monocytes preincubated

Table 1. Effect of LBP depletion and supplementation on serummediated binding of fluorescein isothiocyanate-labeled I.PS to monocytes as assessed by flow cytometry.

\begin{tabular}{lrr}
\hline & \multicolumn{2}{c}{ Fluorescence units } \\
\cline { 2 - 3 } Serum & Pool A* & Pool B \\
\hline $10 \%$ & 47.1 & 27.2 \\
+ control IgG & 37.2 & 28.0 \\
+ anti-rh-LBP IgG & 2.9 & 2.7 \\
+ anti-rh-LBP IgG $+10 \mu \mathrm{g}$ rh-LBP & 66.9 & 55.7 \\
Control (4\% albumin) & 3.1 & 2.8 \\
\hline
\end{tabular}

NOTE: $\mathrm{rh}=$ recombinant human

* High LBP.

${ }^{+}$Low LBP. 
with anti-CDI4 MAb. The specificity of the immunodepletion experiments was assessed by adding back rh-LBP, which restored FITC-LPS binding to monocytes.

Effects of variable $\angle B P$ concentrations on the binding to monocytes. We previously showed that the binding of FITC-LPS to monocytes can be inhibited by preincubation of serum with nonfluorescent LPS [3]; therefore, we preincubated $10 \%$ serum with increasing concentrations of nonfluorescent LPS for $30 \mathrm{~min}$ before adding PBMC with FITC-LPS for an additional $30 \mathrm{~min}$ and assessing binding of FITC-LPS to monocytes by flow cytometry. When $50-75 \mu \mathrm{g} / \mathrm{mL}$. LPS was first added to $10 \%$ serum, there was still partial binding of the $1-\mu \mathrm{g} / \mathrm{mL}$ fluorescent probe to monocytes, suggesting an absence of total saturation of LBP in the preincubation period. Only when using $100 \mu \mathrm{g} / \mathrm{mL}$ unlabeled LPS was FITC-LPS binding suppressed.

Using this protocol, the $\mathrm{IC}_{50}$ (i.e., the concentration of unlabeled LPS that reduced by $50 \%$ the maximal binding of FITC-LPS) was related to the concentration of LBP. The $\mathrm{IC}_{50}$ was threefold higher in pool $\mathrm{A}(12.3 \pm 1.5 \mu \mathrm{g} / \mathrm{mL})$ than in pool $\mathrm{B}(4.3 \pm 0.8 \mu \mathrm{g} / \mathrm{mL}$ : mean $\pm \mathrm{SD}$ of 3 experiments $)$.

These experiments showed that FITC-LPS binding was related to the concentration of LBP. In other experiments (not shown), the limiting factor for LPS binding was actually LBP, not CDI 4. Indeed, monocytes first incubated with 100 $\mu \mathrm{g} / \mathrm{mL}$ LPS did not bind FITC-LPS. However, the same monocytes were able to bind FITC-LPS if fresh LBP was subsequently added, but this binding was suppressed by CDI 4 blockade.

Effects of LBP on TNF release by monocytes. Since binding experiments showed that the amount of LPS bound to monocytes was dependent upon the amount of LBP present in serum, we analyzed the involvement of LBP in the induc-

Table 2. Effect of serum dilution and LBP blockade on binding of fluorescein isothiocyanate-labeled LPS to monocytes and on tumor necrosis factor (TNF) release by peripheral blood mononuclear cells upon LPS challenge.

\begin{tabular}{|c|c|c|c|c|}
\hline \multirow{2}{*}{$\begin{array}{l}\text { PBMC } \\
\text { incubation conditions }\end{array}$} & \multicolumn{2}{|c|}{$\begin{array}{l}\text { LPS binding } \\
\qquad(\mathrm{FU})^{*}\end{array}$} & \multicolumn{2}{|c|}{ TNF release $(\mathrm{pg} / \mathrm{mL})^{\dagger}$} \\
\hline & Pool A & Pool B & Pool $A$ & Pool B \\
\hline \multicolumn{5}{|l|}{ Experiment I } \\
\hline icipool & ND & ND & $910 \pm 120$ & $430 \pm 170$ \\
\hline+ control $\lg G$ & ND & $\mathrm{ND}$ & $920 \pm 150$ & $420 \pm 130$ \\
\hline+ anti-LBP IgG & ND & ND & $20 \pm 25$ & $30 \pm 25$ \\
\hline \multicolumn{5}{|l|}{ Experiment 2} \\
\hline Is pool & 38 & 17 & $800 \pm 220$ & $380 \pm 35$ \\
\hline $0.1 \%$ pool & 15 & 4 & $360 \pm 140$ & $70 \pm 30$ \\
\hline
\end{tabular}

NOTE. Pool $\mathrm{A}=$ high LBP: Pool $\mathrm{B}=$ low LBP: $\mathrm{ND}=$ not done.

* Binding was 2.5 fluorescence units (FU) on cells incubated with control albumin. Assessed by flow cytometry.

${ }^{\dagger}$ Stimulus was $1 \mathrm{ng} / \mathrm{mL}$. LPS. No TNF was detected by bioassay when cells were incubated in medium alone. tion of TNF release by monocytes upon LPS challenge. As shown in table 2, the presence of LBP was a prerequisite for TNF secretion, since treatment of serum with anti-LBP IgG (but not control IgG) suppressed TNF release. The concentration of LBP also determined the response when serum was highly diluted: $0.1 \%$ pool $\mathrm{B}$ was less efficient than $0.1 \%$ pool $A$ in its ability to present FITC-LPS to monocytes and to sustain a TNF response.

\section{Discussion}

The data support the view that LBP is a key serum component in the process of monocyte activation by LPS. The depletion of LBP from sera suppressed both the serum-mediated LPS binding and the TNF production of monocytes stimulated with LPS. In the activation experiments, we used LPS concentrations that are usually found in septic shock patients (nanogram per liter range) [13]. The role played by septin, which could bind LPS and which is inhibited by CDl4 blockade [6], appeared not to be directly linked to TNF production in our experiments, since the mere depletion of LBP from serum efficiently suppressed TNF production. Furthermore, addition of exogenous rh-LBP in the serum depleted from LBP restored LPS binding to monocytes. Thus, activation of monocytes by low LPS concentrations through pathways not related to CDI4 and LBP appeared to be of minor importance.

The data showed that very high quantities of LPS can be presented to monocytes through LBP. In $10 \%$ serum, preincubation with 4-12 $\mu \mathrm{g} / \mathrm{mL}$ LPS was required to diminish by half the maximal subsequent LBP-mediated binding of LPS to monocytes. This demonstrated that LBP in normal plasma was able to enhance LPS binding to monocytes in concentrations far above those found in patients presenting with shock. Furthermore, the factor that limited the binding of LPS to monocytes was the presence of LBP not CD14. In experiments in which monocytes were preincubated with very large concentrations of LPS, followed by washing and incubation with fresh LBP, the LBP could restore LPS binding to monocytes.

The mean concentration of LBP was $18.1 \mu \mathrm{g} / \mathrm{mL}$ in serum of normal donors. This concentration was similar to that previously measured in plasma $(17.8 \mu \mathrm{g} / \mathrm{mL})$ [9]. Both ELISA and RIA gave similar values of LBP in serum. Our data also showed that the ability of LBP to present LPS-LBP complexes to monocytes could be estimated by flow cytometry [9]. LBP levels were higher in blood of septic patients, and the response was not specifically related to gram-negative infection. LBP levels did not have a predictive value for survival in individual patients, and LBP levels are likely to represent a measure of the acute-phase response in these patients.

Normal serum contains 10 to 100 times more LBP than the level needed for monocyte activation. During physiologic conditions and even more during the acute-phase reac- 
tion, LBP is not a limiting factor for LPS-induced monocyte activation. Our data showed that LBP was the only factor present in serum responsible for TNF release of monocytes upon LPS stimulation.

On the other hand, serum contains many factors that can interfere with the presentation of LPS to monocytes, including LPS antibodies and lipoproteins [14, 15], and with monocyte activation, such as antiinflammatory cytokines, including IL-10, IL-13 and IL-4. Different levels of these factors could partially explain the variability of the response of secreted TNF, depending on the donors. However, the present data suggest that when LBP was limiting in highly diluted serum, the serum pool with low LBP concentration was less active than the pool with high LBP concentration in its ability both to present LPS and to sustain TNF release. Thus, this observation and the fact that LBP blockade suppressed TNF release suggest that the level of LBP was a major factor, although the involvement of other factors could not be excluded. Measurements of LBP in biologic and tissue fluids will help determine if LBP is present in sufficient concentration to activate tissue monocytes in the presence of LPS or gram-negative bacteria.

\section{References}

1. Schumann RR, Leong SR. Flaggs GW, et al. Structure and function of lipopolysaccharide binding protein. Science 1990;249:1429-31.

2. Wright SD, Ramos RA, Tobias PS. Ulevitch RJ, Mathison JC. CD14, a receptor for complexes of lipopolysaccharide (LPS) and LPS binding protein. Science 1990:249:1431-3.

3. Heumann D. Gallay P. Barras C. et al. Control of LPS binding and LPS-induced TNF secretion in human peripheral blood monocytes. J Immunol 1992;148:3505-12.

4. Couturier C, Jahns G, Kazatchkine MD. Haeffner-Cavaillon N. Membrane molecules which trigger the production of interleukin-l and tumor necrosis factor $\alpha$ by lipopolysaccharide-stimulated human monocytes. Eur J Immunol 1992;22:146I-6.

5. Lei MG. Morrison DC. Lipopolysaccharide/lipid A receptors on lymphocytes and macrophages. Int Rev Immunol 1990;6:223-35.

6. Wright SD. Ramos RA, Patel M, Miller DS. Septin: a factor in plasma that opsonizes lipopolysaccharide-bearing particles for recognition by CD14 on phagocytes. J Exp Med 1992;176:719-27.

7. Calandra T, Gerain J. Heumann D, Baumgartner JD, Glauser MP, Swiss-Dutch $J 5$ Immunoglobulin Study Group. High circulating levels of interleukin-6 in patients with septic shock: evolution during sepsis, prognostic value and interplay with other cytokines. Am J Med 1991:91:23-9.

8. Pugin J, Schürer-Maly CC, Leturcq D, Moriarty A, Ulevitch RJ, Tobias PS. Lipopolysaccharide activation of human endothelial and epithelial cells is mediated by lipopolysaccharide-binding protein and soluble CD14. Proc Natl Acad Sci USA 1993;90:2744-8.

9. Heumann D, Gallay P, Le Roy D, Glauser MP. Radioimmunoassay versus flow cytometric assay to quantify LPS-binding protein (LBP) concentrations in human plasma. J Immunol Methods 1993; 171:169-76.

10. Leturcq D, VanHook P, Smith R, Tobias P, Ulevitch R, Moriarty A. Generation of monoclonal antibodies to human LBP and their use in the detection of LBP protein in serum. J Cell Biochem 1992;16C (suppl): 161.

11. Baumgartner JD, Heumann D, Gerain J, Weinbreck P, Grau GE, Glauser MP. Association between protective efficacy of anti-lipopolysaccharide (LPS) antibodies and suppression of LPS-induced tumor necrosis factor $\alpha$ and interleukin 6. Comparison of $O$ side chain-specific antibodies with core LPS antibodies. J Exp Med 1990;171:88996.

12. Fisher RA. On the probable error of a coefficient of correlation deduced from a small sample. Metron 1921;1:3-31.

13. van Deventer SJH, Buller HR. Ten Cate JM, Stark A. Pauw W. Endotoxemia: an early predictor of septicemia in febrile patients. Lancet 1988:1:605-8.

14. Flegel WA. Wölpl A. Männel DN. Northoff H. Inhibition of endotoxin-induced activation of human monocytes by human lipoproteins. Infect Immun 1989:57:2237-45.

15. Warren HS, Novitsky TJ, Ketchum PA. Rosjansky PF, Kania S, Siber GR. Neutralization of bacterial lipopolysaccharide by human plasma. J Clin Microbiol 1985;22:590-5. 